\title{
External validation of the Practical Risk Chart for the prediction of delayed cerebral ischemia following aneurysmal subarachnoid hemorrhage
}

\author{
Paul M. Foreman, MD, ${ }^{1}$ Michelle H. Chua, BS, ${ }^{2}$ Mark R. Harrigan, MD, ${ }^{1}$ Winfield S. Fisher III, MD, ${ }^{1}$ \\ R. Shane Tubbs, PhD, ${ }^{3}$ Mohammadali M. Shoja, MD, ${ }^{3}$ and Christoph J. Griessenauer, MD ${ }^{1,4}$ \\ 'Department of Neurosurgery, University of Alabama at Birmingham; ${ }^{3}$ Pediatric Neurosurgery, Children's of Alabama, \\ Birmingham, Alabama; ${ }^{2 H}$ Harvard Medical School; and ${ }^{4}$ Division of Neurosurgery, Beth Israel Deaconess Medical Center, Harvard \\ University, Boston, Massachusetts
}

OBJECTIVE Delayed cerebral ischemia (DCI) following aneurysmal subarachnoid hemorrhage (aSAH) occurs in approximately $30 \%$ of patients. The Practical Risk Chart was developed to predict DCI based on admission characteristics; the authors seek to externally validate and critically appraise this prediction tool.

METHODS A prospective cohort of aSAH patients was used to externally validate the previously published Practical Risk Chart. The model consists of 4 variables: clinical condition on admission, amount of cisternal and intraventricular blood on CT, and age. External validity was assessed using logistic regression. Model discrimination was evaluated using the area under the receiver operating characteristic curve (AUC).

RESULTS In a cohort of 125 patients with aSAH, the Practical Risk Chart adequately predicted $\mathrm{DCl}$, with an AUC of 0.66 (95\% Cl 0.55-0.77). Clinical grade on admission and amount of intracranial blood on CT were the strongest predictors of $\mathrm{DCl}$ and clinical vasospasm. The best-fit model used a combination of the Hunt and Hess grade and the modified Fisher scale to yield an AUC of $0.76(95 \% \mathrm{Cl} 0.675-0.85)$ and $0.70(95 \% \mathrm{Cl} 0.602-0.8)$ for the prediction of $\mathrm{DCl}$ and clinical vasospasm, respectively.

CONCLUSIONS The Practical Risk Chart adequately predicts the risk of $\mathrm{DCl}$ following aSAH. However, the best-fit model represents a simpler stratification scheme, using only the Hunt and Hess grade and the modified Fisher scale, and produces a comparable AUC.

https://thejns.org/doi/abs/10.3171/2016.1.JNS152554

KEY WORDS aneurysm; subarachnoid hemorrhage; ischemia; vasospasm; delayed cerebral ischemia; prediction; Practical Risk Chart; vascular disorders

$\mathrm{D}$ ELAYED cerebral ischemia (DCI) is a recognized complication of aneurysmal subarachnoid hemorrhage (aSAH) that contributes to poor outcome and occurs in approximately $30 \%$ of patients. ${ }^{17,19,20}$ Established risk factors for DCI include large amounts of subarachnoid blood and poor clinical condition on admission. ${ }^{1,6,9}$ In an effort to identify patients at high risk for DCI-related infarction, de Rooij and colleagues developed a Practical Risk Chart (aka Model I) based solely on easily obtainable admission characteristics. ${ }^{5}$ The model consists of 4 predictors (clinical condition on admission, amount of cisternal and intraventricular blood on CT, and age) and was designed for easy use in clinical practice.

The model was both derived and internally validated using a prospectively collected cohort of aSAH patients treated at a single hospital in the Netherlands, raising concern about the generalizability of the Practical Risk Chart. de Rooij et al. expressed this concern when they called for external validation of the Practical Risk Chart in another hospital setting prior to implementation. ${ }^{5}$

ABBREVIATIONS aSAH = aneurysmal SAH; AUC = area under the receiver operating characteristic curve; CARAS = Cerebral Aneurysm Renin Angiotensin System; CTA = CT angiography; $\mathrm{DCl}$ = delayed cerebral ischemia; DSA = digital subtraction angiography; ICU = intensive care unit; $\mathrm{SAH}$ = subarachnoid hemorrhage; WFNS = World Federation of Neurosurgical Societies.

SUBMITTED November 3, 2015. ACCEPTED January 29, 2016.

INCLUDE WHEN CITING Published online May 13, 2016; DOI: 10.3171/2016.1.JNS152554. 
Using a prospective cohort of aSAH patients treated in the United States, we seek to externally validate the Practical Risk Chart for the prediction of DCI in patients with aSAH.

\section{Methods}

A prospective cohort of aSAH patients was used to externally validate the previously published Practical Risk Chart for the prediction of DCI. ${ }^{5}$ All patients were obtained from the CARAS (Cerebral Aneurysm Renin Angiotensin System) study, a prospective, blinded study designed to evaluate associations between common genetic polymorphisms in the renin angiotensin system and occurrence and rupture of cerebral aneurysms, development of cerebral vasospasm and delayed cerebral ischemia, and outcome in aSAH. As a CARAS-based study, this work was exempt from the requirement for institutional review board approval. The study was started in December 2012 and enrollment was completed in February 2015; final results are expected to be published early next year.

\section{Patients}

All patients presenting to the University of Alabama at Birmingham with aSAH were screened for inclusion in the CARAS study. The diagnosis of subarachnoid hemorrhage (SAH) was established on the basis of the admission CT scan or xanthochromia in the cerebrospinal fluid. A ruptured cerebral aneurysm was confirmed by CT angiography (CTA) or digital subtraction angiography (DSA). Exclusion criteria included age $<19$ years and any associated genetic disease/syndrome that could account for the presence of an intracranial aneurysm (e.g., polycystic kidney disease, Turner syndrome, Noonan syndrome, Ehler-Danlos syndrome Type 4, Marfan syndrome, neurofibromatosis Type 1), as well as systemic diseases (e.g., congestive heart failure, cirrhosis, etc.) that could affect the renin-angiotensin system. For the purposes of the current study, patients who died prior to 4 days postictus were also excluded. These patients presented with a high clinical grade and did not survive into the period of highest risk for the development of DCI.

The following admission data were recorded: age, sex, smoking status, history of hypertension, history of ischemic vascular disease, history of diabetes mellitus, clinical condition on admission, and amount of blood on CT. During assessment of the admission data, the authors were blinded for occurrence of DCI. The clinical condition on admission was recorded using the Hunt and Hess grade and the World Federation of Neurosurgical Societies (WFNS) scale.,14 Amount of cisternal blood was dichotomized into thin blood (modified Fisher scale 0-2) and thick blood (modified Fisher scale 3-4)..$^{10}$ Intraventricular blood was dichotomized into less than or greater than the median Hijdra scale score. ${ }^{12}$

Patient cohorts are presented as 3 groups: the development cohort, the internal validation cohort, and the external validation cohort. The development and internal validation cohorts are comprised of prospectively collected patients at a hospital in Utrecht, Netherlands, as was described by de Rooij et al. in their 2013 article. ${ }^{5}$ The external validation cohort is comprised of prospectively collected patients from a tertiary referral center in the southeastern United States.

The presence of a DCI was a secondary outcome measure in the CARAS study, and data, with the exception of the modified Fisher scale and the Hijdra scale, were collected in a prospective manner. The assignment of modified Fisher scale and Hijdra scale were performed blinded to the presence of DCI by the study co-principal investigator (Co-PI) (P.M.F.); cases in which scale scores were not clearly defined were discussed with the study PI (C.J.G.) and a consensus was reached. Clinical grading of patients was performed prior to the placement of an external ventricular drain; in cases where the external ventricular drain was placed prior to arrival, clinical grading was obtained from the hospital records prior to placement. Demographic, clinical, and radiographic data were collected for all patients by the study PI (C.J.G.) and Co-PI (P.M.F.).

\section{General Management}

Patients presenting with aSAH were treated in accordance with contemporary standards of care in the United States, consisting of intensive care unit (ICU) monitoring, treatment of hydrocephalus, early ( $<48$ hours) intervention for aneurysm treatment, oral nimodipine, maintenance of euvolemia, compression stockings, and sequential compression devices. CT scans are routinely obtained in craniotomy patients on postoperative Day 1; however, they are not routinely obtained in endovascular embolization patients. The first-line treatment for clinical vasospasm is hyperdynamic therapy, which includes strict avoidance of hypovolemia, with a goal systolic blood pressure $>160$ $\mathrm{mm} \mathrm{Hg}$, accomplished with either permissive hypertension or vasopressor therapy. Patients with clinical vasospasm refractory to medical treatment are treated in the endovascular suite with intraarterial therapy at the discretion of the neurointerventionalist. Following discharge from the ICU, patients are transferred to a neurological step-down unit or a neurosurgical ward where the staff are specialty-trained in caring for aSAH patients.

\section{Delayed Cerebral Ischemia}

CT scans and MR images were obtained when clinical concerns arose, at the discretion of the critical care team and neurosurgical staff. CT scans were also routinely obtained when the patient was deemed stable for transfer from the ICU to the general care ward. All images were evaluated for evidence of DCI, defined as hypoattenuating regions on $\mathrm{CT}$ that correspond to a vascular distribution, or an MR image demonstrating a hyperintense area on a diffusion-weighted image sequence with a corresponding hypointense apparent diffusion coefficient sequence corresponding to a vascular territory. Infarctions or contusion seen on postoperative Day 1 imaging were considered to be related to the procedure and were not considered to be evidence of DCI. Infarctions identified after postoperative Day 1 were considered DCI.

CT, CTA, and MRI were performed by trained technicians, interpreted by neuroradiologists, and reviewed by neurosurgical staff. DSAs were performed and inter- 
preted by specialty-trained neurointerventionalists, and disagreements were resolved though discussion of the findings, with a final decision made by the senior author (C.J.G.).

\section{Vasospasm}

Clinical vasospasm was defined as the development of a new focal or global neurological deficit or deterioration of at least 2 points on the Glasgow Coma Scale that was not explained by another clinical process, including hydrocephalus, aneurysm rerupture, electrolyte disturbance, seizure, infection, fever, metabolic disturbance, cerebral edema, or surgical complication.

\section{Statistics}

In univariable analysis, categorical variables were compared between groups by the Pearson chi-square test. All variables with a possible association with a clinical vasospasm and DCI $(\mathrm{p}<0.1)$ were entered into a forward stepwise multivariable logistic regression analysis. Variables that failed to meet predictive significance $(p<0.05)$ were eliminated after each run. External validity of the Practical Risk Chart was assessed using logistic regression. Model discrimination was evaluated using the area under the receiver operating characteristic curve (AUC).

\section{Results}

Baseline data from the original development and internal validation cohort are presented with the baseline data from the external validation cohort in Table 1 . The external validation cohort comprised 125 patients (median age 56 years). DCI-related infarction occurred in $110 \mathrm{pa}-$ tients (30\%) in the development cohort, 52 patients $(20 \%)$ in the internal validation cohort, and 29 patients (23.2\%) in the external validation cohort $(\mathrm{p}=0.027)$. The external validation cohort had more patients with a history of hypertension $(\mathrm{p}=0.0001)$ and fewer patients with vascular disease $(\mathrm{p}=0.0019)$. With the exception of a WFNS scale of $3(p=0.0367)$, clinical condition on admission according to the WFNS scale was similar among all cohorts. With respect to the modified Fisher scale, the external validation cohort had a higher rate of Grade $2(\mathrm{p}=$ $0.0001)$ and lower rates of Grades $3(p=0.0001)$ and $4(p$ $=0.000615$ ). Among the 3 cohorts, patients in the development cohort were most likely to not receive treatment for their aneurysm $(\mathrm{p}=0.0001)$ and least likely to undergo coil embolization as aneurysm treatment $(\mathrm{p}=0.00014)$. Clinical vasospasm occurred in 29 patients (23.2\%) in the external validation cohort.

\section{Practical Risk Chart (aka Model I) Performance: Delayed Cerebral Ischemia}

The original multivariable model is presented in Table 2 . The strongest predictors in the development cohort were clinical condition on admission (WFNS scale), amount of cisternal and intraventricular blood on CT, and age. For the combination of these 4 predictors in the development cohort, the AUC after correction for optimism was 0.63 (95\% CI 0.57-0.69). The AUC for the risk chart in the
TABLE 1. Baseline characteristics of the original development and internal validation cohorts and the external validation cohort*

\begin{tabular}{|c|c|c|c|c|}
\hline & Development & $\begin{array}{c}\text { Internal } \\
\text { Validation }\end{array}$ & $\begin{array}{l}\text { External } \\
\text { Validation }\end{array}$ & $p$ Value \\
\hline Admission dates & $\begin{array}{l}\text { Jan 1999- } \\
\text { Jun } 2007\end{array}$ & $\begin{array}{l}\text { Jun 2007- } \\
\text { Dec } 2009\end{array}$ & $\begin{array}{l}\text { Dec 2012- } \\
\text { Feb } 2015\end{array}$ & \\
\hline No. of pts & 371 & 255 & 125 & \\
\hline $\begin{array}{l}\text { DCl-related } \\
\text { infarctions }\end{array}$ & $110(30)$ & $52(20)$ & $29(23.2)$ & 0.027 \\
\hline Women & $261(70)$ & $185(73)$ & $95(76)$ & 0.465 \\
\hline $\begin{array}{l}\text { Median age, years } \\
\text { (range) } \dagger\end{array}$ & $55(18-85)$ & $56(15-87)$ & $56(21-80)$ & UTD \\
\hline $\begin{array}{l}\text { History of hyper- } \\
\text { tension }\end{array}$ & $102(27)$ & $68(27)$ & $73(58)$ & 0.0001 \\
\hline $\begin{array}{l}\text { History of vascu- } \\
\text { lar disease }\end{array}$ & $53(14)$ & $53(21)$ & $9(7)$ & 0.0019 \\
\hline Diabetes mellitus & $16(4)$ & $10(4)$ & $9(7)$ & 0.328 \\
\hline Current smoking & $193(52)$ & $140(61) \ddagger$ & $65(52)$ & 0.0832 \\
\hline \multicolumn{5}{|l|}{$\begin{array}{l}\text { Clinical condition } \\
\text { on admission } \\
\text { by WFNS scale }\end{array}$} \\
\hline 1 & $149(40)$ & $107(42)$ & $65(52)$ & 0.0655 \\
\hline$\|$ & $88(24)$ & $65(26)$ & $24(19)$ & 0.396 \\
\hline III & $30(8)$ & $20(8)$ & $2(2)$ & 0.0367 \\
\hline IV & $53(14)$ & $40(16)$ & $24(19)$ & 0.423 \\
\hline V & $51(14)$ & $23(9)$ & $10(8)$ & 0.0850 \\
\hline \multicolumn{5}{|l|}{$\begin{array}{l}\text { Clinical condition } \\
\text { on admission } \\
\text { by HH grade }\end{array}$} \\
\hline 1 & NR & NR & $12(10)$ & \\
\hline 2 & NR & NR & $64(51)$ & \\
\hline 3 & NR & NR & $27(22)$ & \\
\hline 4 & NR & NR & $16(13)$ & \\
\hline 5 & NR & NR & $6(5)$ & \\
\hline \multicolumn{5}{|l|}{$\begin{array}{l}\text { Amount of blood } \\
\text { by mFisher } \\
\text { scale }\end{array}$} \\
\hline 0 or 1 & $29(8)$ & $28(11)$ & $19(15)$ & 0.0519 \\
\hline 2 & $18(5)$ & $17(7)$ & $42(34)$ & 0.0001 \\
\hline 3 & $111(30)$ & $54(21)$ & $13(10)$ & 0.0001 \\
\hline 4 & $213(57)$ & $156(61)$ & $51(41)$ & 0.000615 \\
\hline \multicolumn{5}{|l|}{$\begin{array}{l}\text { Amount of blood } \\
\text { by Hijdra scale }\end{array}$} \\
\hline $\begin{array}{l}\text { Median } \\
\text { Hijdra } \\
\text { score for } \\
\text { ventricles } \\
\text { (range) } \dagger\end{array}$ & $2(0-12)$ & $3(0-12)$ & $2(0-11)$ & UTD \\
\hline \multicolumn{5}{|l|}{ Site of aneurysm } \\
\hline $\begin{array}{l}\text { Anterior } \\
\quad \text { circulation§ }\end{array}$ & 308 (83) & 226 (89) & $103(82)$ & 0.112 \\
\hline $\begin{array}{l}\text { Posterior } \\
\text { circulation }\end{array}$ & $55(14)$ & $22(9)$ & $22(18)$ & 0.0221 \\
\hline Other & $8(2)$ & $7(3)$ & $0(0)$ & 0.190 \\
\hline
\end{tabular}


» CONTINUED FROM PAGE 1532

TABLE 1. Baseline characteristics of the original development and internal validation cohorts and the external validation cohort*

\begin{tabular}{|c|c|c|c|c|}
\hline & Development & $\begin{array}{c}\text { Internal } \\
\text { Validation }\end{array}$ & $\begin{array}{c}\text { External } \\
\text { Validation }\end{array}$ & $p$ Value \\
\hline \multicolumn{5}{|l|}{$\begin{array}{r}\text { Treatment of } \\
\text { aneurysm }\end{array}$} \\
\hline No treatment & $47(13)$ & $8(3)$ & $0(0)$ & 0.0001 \\
\hline Coiling & $142(38)$ & $131(51)$ & $71(57)$ & 0.00014 \\
\hline Clipping & $182(49)$ & $113(44)$ & $53(42)$ & 0.316 \\
\hline $\begin{array}{l}\text { Other } \\
\text { treatment }\end{array}$ & $0(0)$ & $3(1)$ & $1(1)$ & 0.126 \\
\hline
\end{tabular}

NR = not reported; Dec = December; Feb = February; HH = Hunt and Hess; Jan = January; Jun = June; $\mathrm{mFisher}=$ modified Fisher scale; pts = patients; UTD = unable to determine.

* Values are number of patients (\%) unless otherwise indicated. Table modified from de Rooij et al.: Early prediction of delayed cerebral ischemia after subarachnoid hemorrhage: development and validation of a practical risk chart. Stroke 44(5):1288-1294, 2013. Published with permission of Wolters Kluwer Health, Inc.

$\dagger$ Unable to determine due to missing data from development and internal validation cohorts.

$\ddagger$ Missing data in $10 \%$ of patients.

$\S$ Includes posterior communicating artery aneurysms.

internal validation group was 0.69 (95\% CI 0.61-0.77).

The AUC for the risk chart in the external validation group was 0.66 (95\% CI 0.55-0.77) for DCI-related infarctions. A low risk of DCI-related infarction was pre-

TABLE 2. Multivariable predictors of $\mathrm{DCl}$ after SAH using the original model

\begin{tabular}{lc}
\hline \multicolumn{1}{c}{ Characteristic } & OR $(95 \% \mathrm{Cl})$ \\
\hline Age $<55$ yrs $\dagger$ & $1.37(0.86-2.20)$ \\
\hline Clinical condition on admission by WFNS scale & \\
\hline I & Reference \\
\hline II-III & $1.37(0.77-2.45)$ \\
\hline IV & $1.52(0.75-3.10)$ \\
\hline V & $3.18(1.52-6.62)$ \\
\hline Amount of intracranial blood & \\
\hline Thick cisternal blood on CT $\ddagger$ & $1.77(0.77-4.03)$ \\
\hline Thick intraventricular blood on CT§ & $1.56(0.95-2.57)$ \\
\hline Crude AUC & $0.66(0.60-0.72)$ \\
\hline AUC adjusted for optimismף & $0.63(0.57-0.69)$ \\
\hline
\end{tabular}

$\mathrm{OR}=$ odds ratio.

* Modified from de Rooij et al.: Early prediction of delayed cerebral ischemia after subarachnoid hemorrhage: development and validation of a practical risk chart. Stroke 44(5):1288-1294, 2013. Published with permission from Wolters Kluwer Health, Inc.

$\dagger$ Median value in the development cohort of original model.

$\ddagger$ Thick amount of cisternal blood on CT is defined as a score of 3-4 on the modified Fisher scale.

$\S$ Thick amount of intraventricular blood is defined as a score of at least 3 (> median) on the intraventricular Hijdra scale.

I Adjusted for optimism with bootstrapping techniques.
TABLE 3. Prediction and actual occurrence of DCl-related infarction*

\begin{tabular}{|c|c|c|c|c|}
\hline Risk Group & No. of Pts & $\begin{array}{l}\text { Predicted } \\
\text { Risk }\end{array}$ & $\begin{array}{l}\text { Mean Predicted } \\
\text { Risk }\end{array}$ & $\begin{array}{l}\text { Observed } \\
\text { Infarction }\end{array}$ \\
\hline Low & 44 & $<20$ & 14.8 & 13.6 \\
\hline Average & 69 & $20-40$ & 28.1 & 23.2 \\
\hline High & 12 & $>40$ & 47.3 & 58.3 \\
\hline Total (range) & 125 & - & $25.3(12-61)$ & 23.2 \\
\hline \multicolumn{5}{|c|}{$\begin{array}{l}\text { — = not applicable. } \\
\text { * Values are percent unless otherwise indicated. Table modified from de Rooij } \\
\text { et al.: Early prediction of delayed cerebral ischemia after subarachnoid hemor- } \\
\text { rhage: development and validation of a practical risk chart. Stroke 44(5):1288- } \\
\text { 1294, 2013. Published with permission of Wolters Kluwer Health, Inc. }\end{array}$} \\
\hline
\end{tabular}

dicted in 44 patients (35.2\%), an average risk in 69 patients $(55.2 \%)$, and a high risk in 12 patients $(9.6 \%$; Table $3)$. Of note, age had no effect in the external validation cohort.

\section{Best-fit Model: Delayed Cerebral Ischemia}

In the external validation cohort, the best-fit model used a combination Hunt and Hess grade and modified Fisher scale (Table 4). This resulted in an AUC of 0.76 (95\% CI 0.675-0.85). Figure 1 compares the AUCs of the original model with the best-fit model of the external validation cohort.

Patients with good modified Fisher scale scores (0-2) and good Hunt and Hess grades (1-3) were at low risk of DCI (5.4\%). Patients with poor modified Fisher scale scores (3-4) alone, poor Hunt and Hess grades (4-5) alone, and poor modified Fisher scale scores with poor Hunt and Hess grades were at high risk of DCI (39.1\%, $45.5 \%$, and $52.9 \%$, respectively).

\section{Best-Fit Model: Clinical Vasospasm}

The AUC for clinical vasospasm using the best-fit model (Hunt and Hess grade and modified Fisher scale) in the external validation cohort was 0.70 (95\% CI 0.602-0.8; Table 5).

\section{Discussion}

Delayed cerebral ischemia represents a potentially modifiable complication of aSAH that contributes to poor outcome. ${ }^{17,20}$ Numerous grading scales, of varied complexity, have been developed in an attempt to identity high risk patients. ${ }^{2,4,5,9-11,18}$ The Practical Risk Chart developed by

TABLE 4. Best-fit model applied to DCI

\begin{tabular}{|c|c|c|c|c|}
\hline Predictor & $\begin{array}{l}\text { Multivariate } \\
\text { Coefficient }\end{array}$ & SE & OR & $p$ Value \\
\hline HH grade 4-5 & 0.8896 & 0.5354 & $2.43(1.43-4.16)$ & 0.0966 \\
\hline $\begin{array}{l}\text { Modified Fisher } \\
\text { score 3-4 }\end{array}$ & 2.0671 & 0.5853 & $7.90(4.40-14.2)$ & 0.0004 \\
\hline
\end{tabular}




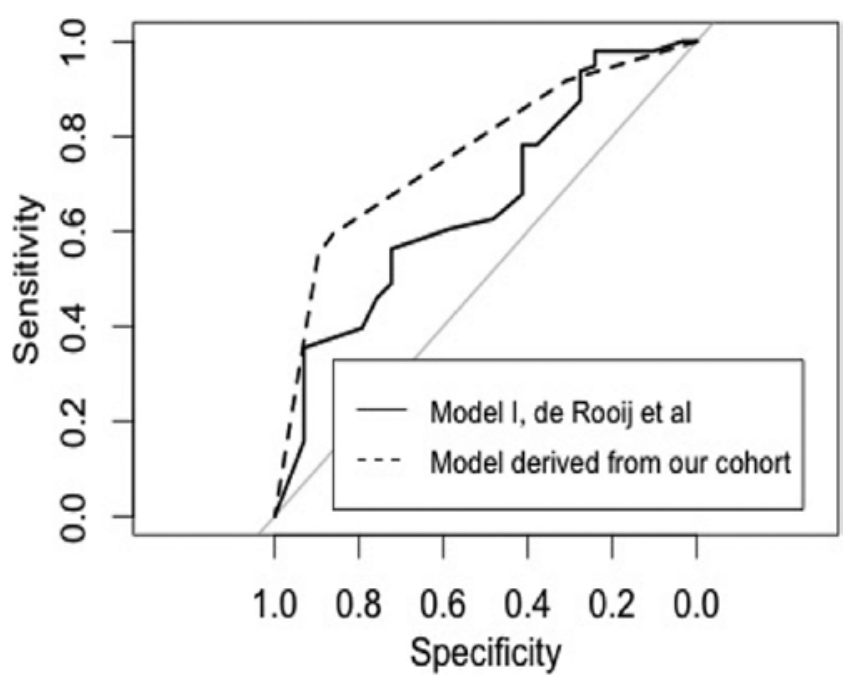

FIG. 1. Graph showing AUCs comparing Model I developed by de Rooij et al. ${ }^{5}$ and our best-fit model for $\mathrm{DCl}$.

Rooij et al. is based on 4 admission characteristics (clinical condition on admission, amount of cisternal and intraventricular blood on CT, and age), making it a tool for the initial assessment of patients with aSAH. ${ }^{5}$ We have examined the external validity of the Practical Risk Chart in a separate hospital system, finding a comparable AUC of 0.66 (AUC of 0.69 in the internal validation cohort). Despite adequate model performance, the inclusion of 4 variables, some of which are not commonly used in the United States (WFNS scale, Hijdra scale), renders it cumbersome for daily use.

Clinical condition on admission and amount of subarachnoid hemorrhage are recognized risk factors for clinical vasospasm and DCI.1,4,10 The clinical condition of aSAH patients is commonly reported as the Glasgow Coma Scale (originally described for traumatic brain injury), ${ }^{21}$ the WFNS scale, ${ }^{7}$ or Hunt and Hess grade, ${ }^{14}$ with the latter being the most common in the United States. Multiple scales also exist to describe the amount of intracranial blood, including the Fisher scale, ${ }^{9}$ the modified Fisher scale, ${ }^{10}$ and the Hijdra scale. ${ }^{12}$ While the Fisher scale is the most widely used, the modified Fisher scale is easily understood and predicts clinical vasospasm more accurately as it accounts for the independent additive effects of cisternal and intraventricular blood..$^{10}$ The Hijdra scale, in which the amount of blood in 10 basal cisterns/ fissures and 4 ventricles is graded separately, is more comprehensive than the 4-point modified Fisher scale and has been promoted by some authors. ${ }^{8,12,13}$ However, it is unfamiliar to most neurosurgeons and too tedious for routine use in the absence of strong evidence of its superiority. The best-fit model for our cohort used only the Hunt and Hess grade and the modified Fisher scale, with an AUC of 0.76 . The Hijdra scale was predictive of clinical vasospasm $(\mathrm{p}=0.0213)$ but not DCI $(\mathrm{p}=0.489)$ in univariable analysis. Our findings confirm the utility of conventional predictors, which were not found to be inferior to more complicated systems.

It is presently unclear if and how age affects the risk
TABLE 5. Best-fit model applied to clinical vasospasm

\begin{tabular}{|c|c|c|c|c|}
\hline Predictor & $\begin{array}{r}\text { Multivariate } \\
\text { Coefficient }\end{array}$ & SE & OR & $p$ Value \\
\hline $\mathrm{HH}$ grade $4-5$ & 1.0097 & 0.5191 & $2.74(1.63-4.61)$ & 0.0518 \\
\hline $\begin{array}{c}\text { Modified Fisher } \\
\text { score 3-4 }\end{array}$ & 1.2189 & 0.4932 & $3.38(2.07-5.54)$ & 0.0135 \\
\hline
\end{tabular}

of vasospasm and DCI. In previous reports, older age has been associated with a higher incidence of clinical vasospasm and DCI. ${ }^{15,23}$ However, other authors have observed clinical vasospasm more frequently in younger patients. ${ }^{16,22}$ Increased stiffness of the cerebral vasculature may account for a lower incidence of angiographic vasospasm in the elderly. ${ }^{21}$ However, older patients often have reduced cerebral and cardiac reserve, potentially increasing the risk of DCI following vasospasm. In the current series, age was not an independent predictor of clinical vasospasm $(<55$ years vs $\geq 55$ years: $p=0.705$; age as a numerical variable: $\mathrm{p}=0.715)$ or DCI $(<55$ years vs $\geq 55$ years: $p=0.365$; age as a numerical variable: $p=0.929$ ). The incidence of DCI following clinical vasospasm was not significantly different for younger and older patients ( $72.7 \%$ vs $77.8 \%, p=1)$. In addition, advanced age is associated with less favorable outcomes, ${ }^{15}$ likely related to medical comorbidities and decreased physiological reserve, which has led some authors to exclude age as a variable in analogous grading scales. ${ }^{4}$

The best-fit model (Hunt and Hess grade and modified Fisher scale) was also evaluated with respect to predicting clinical vasospasm, resulting in an AUC of 0.70 . This was an expected finding, as clinical vasospasm and DCI are known to be highly associated. ${ }^{3}$

For a predictive model to be useful it must use easily obtainable data points, be simple, and be accurate. While the Practical Risk Chart ${ }^{5}$ performs adequately (AUC 0.66 in the external validation cohort), it requires multiple data points and an actual chart. In contrast, the VASOGRADE ${ }^{4}$ (WFNS scale and modified Fisher scale) and our best-fit model (Hunt and Hess grade and modified Fisher scale) use only 2 predictive variables and produce comparable AUCs of 0.63 and 0.76 , respectively. The difference between VASOGRADE and our best-fit model is simply the classification scheme used for clinical condition on admission (WFNS scale vs Hunt and Hess grade). While it would be reasonable for clinicians to simply substitute the 5-tiered Hunt and Hess grade for the 5-tiered WFNS scale into the VASOGRADE to identify each patient's colored (green, yellow, and red) risk category, we encourage clinicians to recognize the clinical implications of a high admission clinical grade and large amount of intracranial hemorrhage with respect to risk of clinical vasospasm and DCI. This should be viewed in context, rather than preset categories, with clinical acumen individualizing monitoring strategies (i.e., transcranial Doppler ultrasound, cerebral angiogram), disposition (i.e., ICU or general care ward), and aggressiveness of treatment (i.e., hyperdynamic therapy or angioplasty). 


\section{Limitations}

This study was limited to a prospective cohort of patients enrolled in the CARAS study at a single institution in the southeastern United States. Selection bias into the study was not felt to meaningfully impact study enrollment, as only 2 patients with confirmed aSAH were excluded. Both of these patients had experienced rupture of a previously treated aneurysm. All eligible patients were successfully and consecutively enrolled. When compared with the development and internal validation cohorts of the original Practical Risk Chart manuscript, ${ }^{5}$ the total number of patients was relatively small. Despite this, the AUCs of the 3 groups, the development, internal validation, and external validation cohorts, were similar (0.63, 0.69 , and 0.66 , respectively). While a single institution study can lead to concerns about generalizability, the patient population seen in a tertiary referral center in the southeastern United States is actually quite different from the Dutch population used in the original manuscript (Table 1). Defining DCI is another potential source of error. The current study chose to define DCI as nontreatmentrelated cerebral infarctions; however, patients treated with endovascular embolization did not routinely undergo postoperative Day $1 \mathrm{CT}$, introducing the possibility of a treatment-related infarct being falsely attributed to DCI.

\section{Conclusions}

The Practical Risk Chart adequately (AUC 0.66) predicts the risk of DCI following aneurysmal subarachnoid hemorrhage in a disparate healthcare system from that where it was developed. However, the best-fit model represents a simpler stratification scheme, using only Hunt and Hess grade and the modified Fisher scale, and produces a comparable AUC of 0.76. Clinical grade on admission and amount of intracranial blood are strong predictors of clinical vasospasm and DCI in patients presenting with aSAH.

\section{Acknowledgments}

We would like to thank the Brain Aneurysm Foundation for their generous support of the Cerebral Aneurysm Renin Angiotensin System study.

\section{References}

1. Adams HP Jr, Kassell NF, Torner JC, Haley EC Jr: Predicting cerebral ischemia after aneurysmal subarachnoid hemorrhage: influences of clinical condition, CT results, and antifibrinolytic therapy. A report of the Cooperative Aneurysm Study. Neurology 37:1586-1591, 1987

2. Crobeddu E, Mittal MK, Dupont S, Wijdicks EF, Lanzino G, Rabinstein AA: Predicting the lack of development of delayed cerebral ischemia after aneurysmal subarachnoid hemorrhage. Stroke 43:697-701, 2012

3. Crowley RW, Medel R, Dumont AS, Ilodigwe D, Kassell NF, Mayer SA, et al: Angiographic vasospasm is strongly correlated with cerebral infarction after subarachnoid hemorrhage. Stroke 42:919-923, 2011

4. de Oliveira Manoel AL, Jaja BN, Germans MR, Yan H, Qian W, Kouzmina E, et al: The VASOGRADE: a simple grading scale for prediction of delayed cerebral ischemia after subarachnoid hemorrhage. Stroke 46:1826-1831, 2015
5. de Rooij NK, Greving JP, Rinkel GJ, Frijns CJ: Early prediction of delayed cerebral ischemia after subarachnoid hemorrhage: development and validation of a practical risk chart. Stroke 44:1288-1294, 2013 (Erratum in Stroke 44:e61, 2013)

6. de Rooij NK, Rinkel GJ, Dankbaar JW, Frijns CJ: Delayed cerebral ischemia after subarachnoid hemorrhage: a systematic review of clinical, laboratory, and radiological predictors. Stroke 44:43-54, 2013

7. Drake CG, Hunt WE, Kassell N, Pertuiset B, Sano K, Teasdale G, et al: Report of World Federation of Neurological Surgeons Committee on a Universal Subarachnoid Hemorrhage Grading Scale. J Neurosurg 68:985-986, 1988

8. Dupont SA, Wijdicks EF, Manno EM, Lanzino G, Rabinstein AA: Prediction of angiographic vasospasm after aneurysmal subarachnoid hemorrhage: value of the Hijdra sum scoring system. Neurocrit Care 11:172-176, 2009

9. Fisher CM, Kistler JP, Davis JM: Relation of cerebral vasospasm to subarachnoid hemorrhage visualized by computerized tomographic scanning. Neurosurgery 6:1-9, 1980

10. Frontera JA, Claassen J, Schmidt JM, Wartenberg KE, Temes R, Connolly ES Jr, et al: Prediction of symptomatic vasospasm after subarachnoid hemorrhage: the modified fisher scale. Neurosurgery 59:21-27, 2006

11. Gonzalez NR, Boscardin WJ, Glenn T, Vinuela F, Martin NA: Vasospasm probability index: a combination of transcranial Doppler velocities, cerebral blood flow, and clinical risk factors to predict cerebral vasospasm after aneurysmal subarachnoid hemorrhage. J Neurosurg 107:1101-1112, 2007

12. Hijdra A, Brouwers PJ, Vermeulen M, van Gijn J: Grading the amount of blood on computed tomograms after subarachnoid hemorrhage. Stroke 21:1156-1161, 1990

13. Hijdra A, van Gijn J, Nagelkerke NJ, Vermeulen M, van Crevel H: Prediction of delayed cerebral ischemia, rebleeding, and outcome after aneurysmal subarachnoid hemorrhage. Stroke 19:1250-1256, 1988

14. Hunt WE, Hess RM: Surgical risk as related to time of intervention in the repair of intracranial aneurysms. J Neurosurg 28:14-20, 1968

15. Lanzino G, Kassell NF, Germanson TP, Kongable GL, Truskowski LL, Torner JC, et al: Age and outcome after aneurysmal subarachnoid hemorrhage: why do older patients fare worse? J Neurosurg 85:410-418, 1996

16. Magge SN, Chen HI, Ramakrishna R, Cen L, Chen Z, Elliott $\mathrm{JP}$, et al: Association of a younger age with an increased risk of angiographic and symptomatic vasospasms following subarachnoid hemorrhage. J Neurosurg 112:1208-1215, 2010

17. Pegoli M, Mandrekar J, Rabinstein AA, Lanzino G: Predictors of excellent functional outcome in aneurysmal subarachnoid hemorrhage. J Neurosurg 122:414-418, 2015

18. Qureshi AI, Sung GY, Razumovsky AY, Lane K, Straw RN, Ulatowski JA: Early identification of patients at risk for symptomatic vasospasm after aneurysmal subarachnoid hemorrhage. Crit Care Med 28:984-990, 2000

19. Roos YB, de Haan RJ, Beenen LF, Groen RJ, Albrecht $\mathrm{KW}$, Vermeulen M: Complications and outcome in patients with aneurysmal subarachnoid haemorrhage: a prospective hospital based cohort study in the Netherlands. J Neurol Neurosurg Psychiatry 68:337-341, 2000

20. Rosengart AJ, Schultheiss KE, Tolentino J, Macdonald RL: Prognostic factors for outcome in patients with aneurysmal subarachnoid hemorrhage. Stroke 38:2315-2321, 2007

21. Teasdale G, Jennett B: Assessment of coma and impaired consciousness. A practical scale. Lancet 2:81-84, 1974

22. Torbey MT, Hauser TK, Bhardwaj A, Williams MA, 
Ulatowski JA, Mirski MA, et al: Effect of age on cerebral blood flow velocity and incidence of vasospasm after aneurysmal subarachnoid hemorrhage. Stroke 32:2005-2011, 2001

23. Yoshimoto Y, Kwak S: Age-related multifactorial causes of neurological deterioration after early surgery for aneurysmal subarachnoid hemorrhage. J Neurosurg 83:984-988, 1995

\section{Disclosures}

The authors report no conflict of interest concerning the materials or methods used in this study or the findings specified in this paper.

\section{Author Contributions}

Conception and design: Foreman, Griessenauer. Acquisition of data: Foreman, Griessenauer. Analysis and interpretation of data: Foreman, Chua, Griessenauer. Drafting the article:

Foreman. Critically revising the article: all authors. Reviewed submitted version of manuscript: Foreman, Harrigan,

Griessenauer. Approved the final version of the manuscript on behalf of all authors: Foreman. Statistical analysis: Chua. Study supervision: Foreman, Harrigan, Fisher, Tubbs, Shoja, Griessenauer.

\section{Correspondence}

Paul M. Foreman, Department of Neurosurgery, University of Alabama at Birmingham, Faculty Office Tower 1005, 510 20th St. S, Birmingham, AL 35294. email: pforeman@uabmc.edu. 